\title{
A Study on Marriage Views of Chinese and Japanese Youths from Perspectives of Blind Dates and Konkatsu
}

\author{
Youqianyan Zhuo \\ School of Foreign Languages, Fuzhou University, Fuzhou, 350108, China
}

\begin{abstract}
With rapid social development and economic progress, a myriad of social issues have occurred in China and Japan in recent years, including never-married employees above the average age, late marriage, and late childbirth. The young people's marital status has attracted widespread concern. It thus created distinctive yet similar products of the era-blind dates and konkatsu. This paper studied the new blind dates in China and konkatsu in Japan in the contemporary era. It first compared blind dates and konkatsu from three perspectives, including social background, patterns of manifestations, and social impact. Based on such findings, it analyzed the motivations for blind dates and konkatsu, as well as the marriage views of Chinese and Japanese youths reflected by such mate-selection standards.
\end{abstract}

Keywords: Japan and China, blind date, konkatsu, young people, views on marriage and love

\section{INTRODUCTION}

Marriage views are crucial components of one's values. They refer to men's and women's fundamental views and attitudes to love and marriage. Therefore, marriage views play an important role in guiding individuals' mate selection and marriage life. Meanwhile, the formation and changes of marriage views are closely related to economic development, the educational level, and the social environment. With the rapid social development and economic progress of Japan and China in recent years, earthshaking changes have taken place in people's ideas, concepts, and experience. Correspondingly, a myriad of problems concerning marriage difficulties occurs in China and Japan, including never-married people above the average age, late marriage, and late childbirth. In this context, young people's marriage life is attracting widespread attention from society. The Chinese blind date, which has existed for thousands of years, becomes popular again in many Chinese cities through emerging media such as TVs and the Internet. Also, a large number of youths join the blind-date team actively or passively. Similarly, konkatsu became the synonym for a series of activities for the young people to get married, such as fellowship blind dates and a series of activities for improving qualities. This term was even elected as the most popular term of the year in Japan twice.

According to a literature review, the Chinese academic circle mostly conduct independent studies on Chinese new blind dates and Japanese konkatsu, while few studies involve the comparative analysis of both. Regarding blind dates, most studies focus on the development status and directions of TV blind date programs. Regarding konkatsu, Dan Zhao analyzed the background, form, solution effectiveness, and social significance of konkatsu. [1] Jingxian Reng explored contemporary Japanese youths' marriage views from the perspective of konkatsu ${ }^{[2]}$. Conversely, Japanese scholars focus on studying the social impact of konkatsu. For example, Hiroshi Kitai studied the impact of konkatsu on the phenomenon of sub-replacement fertility and regional regeneration ${ }^{[3]}$. Shou Suzuki paid emphasis on studying the impact of selecting mates according to one's conditions in the konkatsu market. ${ }^{[4]}$ The new blind dating activities of China and Japan are products of the era under multiple factors. Each has a distinctive era background, the form of manifestation, and social impact. Meanwhile, both reflect the marriage views held by Chinese and Japanese youths somehow. This paper compared Chinese blind dates and Japanese konkatsu on the existing basis to explore the marriage views of Chinese and Japanese youths. The comparative study on Chinese blind dates and Japanese konkatsu is conducive for gaining in-depth knowledge of societies in both countries. Furthermore, it provides revelations for solving Chinese youths' marriage difficulties.

\section{A Comparison of Similarities and Differences between Blind Dates and Konkatsu}

The blind date refers to a form where a man and woman meet and communicate with each other through the recommendation of friends and relatives to establish romantic and marital relationships. Ever since the advent of the $21^{\text {st }}$ century, a series of new blind dates, including blind dates on TV programs and the Internet, have been derived from traditional blind dates. Japanese konkatsu originated from the abbreviation of inauguration activities in Japanese. It refers to the situation where contemporary Japanese youths actively participate in fellowship dating and improve their qualities to get married, just like 
attending many interviews for a job.

\subsection{A Comparison of Social Backgrounds for Blind Dates and Konkatsu}

\subsubsection{Social Background for Blind Dates}

As one of China's traditional marriage customs, the blind date has existed since ancient times. With accelerating urban modernization and prospering market economy, people's life pace is quickened. Meanwhile, great changes have taken place in people's views and values. Under high work pressure, living costs, and occupational mobility, a large batch of marriageable leftover men and women have occurred in the metropolis, who have to postpone marriage for various reasons. However, a majority of parents take the traditional concepts of "getting married and starting a career" seriously. Thinking that helping children get married is a duty of their life, parents inevitably intervene in children's marriage in succession. Some help to arrange blind dates for children, while some even intervene in children's mate selection.

The distinctive views of two generations of people have expedited the resurgence of this social phenomenon. Blind dates were considered as products of arranged marriage in the old society and now stand for backwardness and oppression. Nowadays, an increasing number of young people choose blind dates passively and actively. Although many young people start to experience the anxiety of being leftover, a large proportion accepts blind dates perfunctorily because they are forced by parents to get married. Of course, some young people, who have high mate-selection standards yet no suitable options, have blind dates to expand their social circles.

\subsubsection{Social Background for Konkatsu}

After the bubble economy crashed in the 1990s, the Japanese economy saw a considerable retrogression. There occur an increasing number of people who uphold negative attitudes toward the future. Some women place their hope in marrying high-income men to live a stable life. For this reason, more women wish to find men that meet their conditions through konkatsu. Affected by collectivism, many young people think they will be accepted by society through marriage. [5] Sub-replacement fertility and population aging are two problems perplexing Japanese society. Now young people's selection of late marriage or even no marriage undoubtedly aggravates sub-replacement fertility. Correspondingly, there are public social opinions that encourage young people to walk down the aisle positively. In this context, an increasing number of youths choose to join konkatsu.

\subsubsection{A Comparison of Social Backgrounds for Blind Dates and Konkatsu}

Both blind dates and konkatsu are means for contemporary youths to date fast and get married. Nowadays, young people in China and Japan fail to get married for various reasons. Also, few people can select an ideal partner. For this reason, people all choose to expand their social interactions through blind dates or konkatsu. There is one difference. Chinese single youths have to take blind dates under their parents' orders. By comparison, young Japanese attend konkatsu according to their own will, though they are affected by social voices more or less.

\subsection{A Comparison of Manifestation Patterns of Blind Dates and Konkatsu}

\subsubsection{Manifestation Patterns of Blind Dates}

Nowadays, the traditional blind dates arranged through parents' and friends' recommendations still exist. Also, various offline blind-date corners and gatherings are ubiquitous in large cities. For example, parents set up a stall and put up boards spontaneously at a Shanghai park. For another example, a ten-thousand-member blind date assembly is held at the end of each month in Nanjing Baima Park.

Besides, there are some original forms of blind dates and online TV blind-date programs, such as If You Are the One, Somebody to Love, and It is You. These programs immediately become popular in China after being premiered.

Meanwhile, various marriage and dating websites, such as Jiayuan.com, Zhenai.com, and Baihe.com, are all influential. For example, Jiayuan.com has attracted 50,000 newly registered members since it was set up in 2003. By 2010, there had been more than 500,000 registered members. ${ }^{[6]}$

\subsubsection{Manifestation Patterns of Konkatsu}

Japanese konkatsu have diverse forms. Apart from the traditional konkatsu similar to Chinese traditional blind dates, there are new forms of konkatsu activities. White-collar men and women prefer having party-style blind dates after work and call friends to attend a big party. In this way, they can meet the opposite sex with similar classes and hobbies faster.

The same as China, there are many blind date websites in Japan. People who have and attach importance to equal conditions clarify the requirements for partners before starting online blind dates. It not only saves much time and costs but is also efficient. Besides, the konkatsu based on online data matching is also an optional choice for many people. If a person can be matched to someone with similar interests on the first date, it will enhance their 
willingness to increase dates and getting married more easily.

The Japanese konkatsu is not confined to small scale blind dates but includes street assemblies. For example, many men and women get together on the streets and lanes. One assembly may be participated by hundreds to one thousand men and women. Now similar street parties can be found on all streets and lanes in Japan ${ }^{[7]}$.

Apart from various forms of social interactions, many konkatsu lectures are given in Japan. Single men and women can meet each other by attending such konkatsu lectures to improve their qualities faster. In this way, they will be more popular in the marriage and love market.

\subsubsection{A Comparison of Manifestation Patterns of Blind Dates and Konkatsu}

Chinese and Japanese youths have incorporated elements of the new era to traditional blind dates and konkatsu. Now, the media and the Internet are efficiently used to expand the social network more efficiently. There is one striking difference. Chinese youths are fond of following the latest trend and mainly use such new media as social media, televisions, and the Internet. By comparison, Japanese youths adopt more diversified forms of blind dates. For one thing, Japanese youths use new media. For another, they do not reject dating by offline means. Besides, there is a large number of offline ways to make friends. Some Japanese even attend konkatsu lectures that help them to improve themselves.

\subsection{A Comparison of Social Impacts of Blind Dates and Konkatsu}

\subsubsection{Social Impacts of Blind Dates}

According to the data of Report on Marriage and Love Indexes 2017 released by Zhenai.com, about $31 \%$ of single men and women chose to get rid of the single state through friends and relatives' recommendation; $23 \%$ registered on blind date websites; $20 \%$ participated in workplace activities; $15 \%$ participated in blind-date activities; $11 \%$ attended classmates' reunions. ${ }^{[8]}$ As the number of single people increases, diverse blind dates have nearly become the primary choice for young people who want to get rid of the single state.

Besides, the craze of blind dates attracted widespread attention for TV blind date programs. The marriage views expressed by guests in TV programs are particularly eye-catching. For example, there occurred such a money-worshiping statement of "I would rather cry in the BMW car than laugh on a bicycle", which attracted heated discussions nationwide. The television is a popular media. Thus the mate-selection standards put forward by the program also exert a widespread impact on young people's values and marriage views.
The craze of blind dates also led to one social phenomenon - the blind-date economy. Some scholars studied and analyzed the blind dates prevailing in cities of the Yangtze River Delta, such as Nanjing, Hangzhou, and Shanghai. According to the study findings, the blind-date market in the Yangtze River Delta creates business opportunities worth billions of RMB every year. ${ }^{[9]}$ At every large scale blind-date assembly, merchants provide sponsorship; the media make promotions; participants pay membership fees. Meanwhile, the media contacts merchants to distribute notices, expands the brand effect, and attracts more merchants. It helps to attract more targets for blind dates and generate high economic revenues.

\subsubsection{Social Impact of Konkatsu}

Konkatsu has both positive and negative impacts on Japanese society. Regarding positive impacts, konkatsu provides many young people with opportunities for realizing the ideal type and helps them to find ideal partners through data matching. Onet, a top-notch website in Japanese konkatsu industry, released survey data that showed about $21 \%$ of members got married in 2012 . It meant one in five people successfully got married through marriage websites. ${ }^{[10]}$ Meanwhile, the konkatsu market has brought tremendous business opportunities for merchants. Therefore, the operating rate of enterprises such as Lotte and IBJ increases year by year. Besides, the Konkatsu industry has contributed to recovering the Japanese economy.

Regarding negative impacts, konkatsu refugee has been a social phenomenon. After attending konkatsu activities for one and a half years to get married, the number of people who are fatigued about marriage increases year by year. Moreover, the people who have heterophobia ${ }^{1}$ have severer rather than alleviated symptoms after attending konkatsu activities. Meanwhile, frequent occurrence of konkatsu-based telecommunication frauds is a heatedly discussed topic.

\subsubsection{A Comparison of Social Impacts of Blind Dates and Konkatsu}

Although blind dates and konkatsu occurred in China and Japan, both of them have achieved noticeable achievements. Apart from reducing the young people's anxieties about marriage and love, they have driven the emergence and development of the marriage industry. Every coin has two sides. On the other hand, the

\footnotetext{
${ }^{1}$ Heterophobia: On the one hand, one subconsciously has a strong desire to hang out with the opposite sex. On the other hand, one has severe anxieties and is extraordinarily anxious and scared in front of the opposite sex. Some even have the psychological symptom of having vain hope for the opposite sex.
} 
money-worshiping inclination revealed by partial guests in Chinese TV blind date programs unfavorably guides the shaping up of the young people's values. Meanwhile, konkatsu refugees also occurred in Japan.

\section{A STUDY OF CHINESE AND JAPANESE YOUTHS' MARRIAGE VIEWSFROMPRESPECTIVES OF BLIND DATES AND KONKATSU}

\subsection{Blind Dates and Chinese Youths' Marriage Views}

As contemporary Chinese youths have open views on marriage and love, many people calmly accept the way to meet the opposite sex through blind dates. Most of these people have blind dates to know the opposite sex and quickly set up a romantic relationship fast. Some survey findings show that $25.6 \%$ of people receiving blind dates were interviewed. About $75.8 \%$ of postgraduates clearly said that they were forced to have blind dates, and $70.6 \%$ were forced by family pressure. ${ }^{[1]}$ Thus it can be seen that a small proportion of young people and particularly people with a high educational level have blind dates out of pressure from parents and friends.

The men and women accepting new blind dates somehow reflect contemporary young people's marriage views. According to the Report on Marriage and Love Index 2017 released by Zhenai.com, nearly $50 \%$ of single women and men believe that they can meet true love, and $27 \%$ thought true love should be achieved through conditions. Regarding requirements for mate selection, personality, financial conditions, appearance, workability, and height are factors that men and women consider with priority (see Figure 1). Thus it can be seen that most people think love is still a crucial component of marriage. Despite this, young people attach importance to the roles of social and economic factors. Now the materialistic inclination becomes increasingly prominent.

\title{
Ranking of Mate-selection Factors Considered by Men and Women
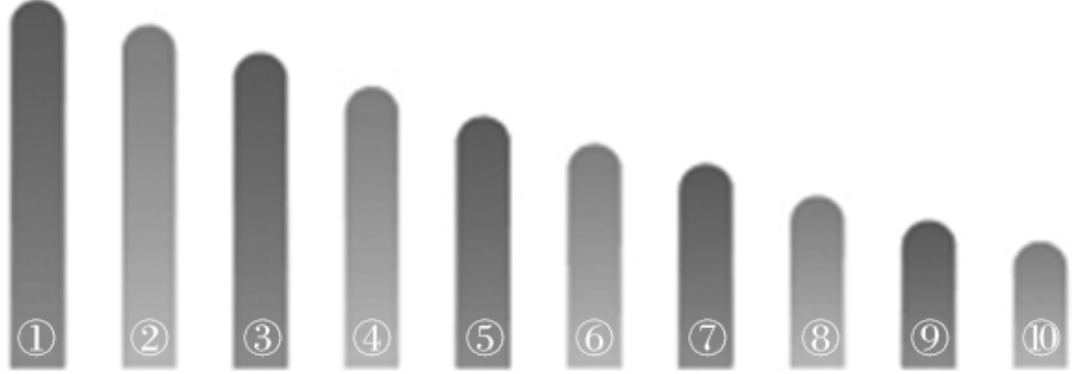

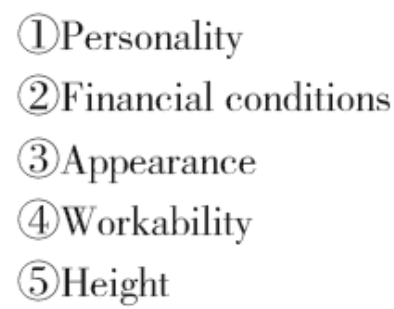

\author{
(6) Physical quality \\ (7)Family background \\ (8)Marital history \\ (9)Region \\ (10Educational background
}

Figure 1 Ranking of mate-selection factors considered by men and women

\subsection{Konkatsu and Japanese Youths' Marriage Views}

Japanese traditional marriage views are similar to those of China. In other words, people get married to set up the community of family. However, many Japanese youths think marriage is less important than it used to be under the impact of individualistic thinking. Thus an increasing number of people choose to be single to maximize their self-worth. On the other hand, some studies show that at least $45 \%$ of people want to get married when late marriage and never-marriage prevail. Many young people get married "to be with the beloved ones", "to have children", and "to make parents relieved". Among these 
[1] Z . Dan. A study on Japanese Konkatsu [D]. Hainan University, 2015.04.01

appropriate partners for marriage" and thus chose to expand their social circle through konkatsu ${ }^{[12]}$.

Although many youths have strong marriage awareness, the difference between mate-selection views is a major reason why they can hardly get married. After the bubble economy crashed, an increasing number of people are unwilling to continue working hard in economic distress. As a result, herbivore men $^{2}$ grow with each passing day. According to relevant surveys, more than $70 \%$ of men thought they were herbivore men, while $87.2 \%$ of women wished to date with carnivorous $\operatorname{men}^{3}{ }^{[13]}$ Owing to the economic recession, women become increasingly realistic. In the meantime, more than $40 \%$ of men have no financial support for them to get married ${ }^{[14]}$. Such a mismatched mating order makes it difficult for many people to find appropriate partners when their financial conditions and mating range remain fixed. Thus an increasing number of people join konkatsu to improve their standards and know more people of the opposite sex that meet their mate-selection criteria.

\section{CONCLUSIONS}

The marriage view is one of the important perspectives for measuring and observing social changes. The resurgence of Chinese blind dates and prevalence of Japanese konkatsu reflect the importance of marriage in Chinese and Japanese societies, as well as the social status of marriage difficulties for Chinese and Japanese youths. As a result, diverse new blind date activities have sprung up in both countries. Both Japanese and Chinese youths attach importance to love in blind dates and konkatsu. Thus they think marriage means being with the beloved one for a whole life. The Chinese economy enjoys rapid development, while the Japanese economy remains at a standstill. Thus the economic condition is a crucial condition for the mate-selection process. Blind dates and konkatsu have not only helped many young people to walk down the aisle but also driven the emergence of the marriage and love industry. Thus they considerably promote economic development.

\section{REFERENCES}

\footnotetext{
${ }^{2}$ Herbivorous men was abstracted from the online editorial article of professional writer Maki Fukasawa in 2006. "Young men aged between 20 and 30 are less intimate to the opposite sex. Nor are they confined to male chauvinism." Good-natured, soft, considerate, care-loving, safe, and secure men are known as herbivorous men.

${ }^{3}$ Carnivorous men are contrary to herbivorous men. They have a masculist thinking, grand character, bravery, enthusiasm, and machismo. With characters similar to carnivores, these men are referred to as carnivorous men.
}

[2] R . Jingxian. An insight into Japanese youths' marriage views from the perspective of konkatsu [D], Hunan University, 2016. 04. 25

[3] H. Kitai. Challenge to decrease in population and revitalization of the community (23) Support to young people's provided by cooperation and citizen volunteers in Miki,Hyogo [J]. Governance, 2017.03, pp101-103.

[4] S. Suzuki, K. Sudou, Y. Terada , M. Oguro . The effect of academic background, income, and appearance on marriage and spouse choice behavior: mechanisms involved in marriage counseling services. Theory and Method [J], 2018, no.33(2), pp.167-181..

[5] https://www.konkatu-support.com/nannnotame-nazes uru/

[6] Betul Demir. A Brief Study on the Reasons for Blind-date Craze in Recent Years and Its Impact [J], Beauty Times (Urban), 2015.05.25, pp. 13-14..

[7] R . Jingxian. An insight into Japanese youths' marriage views from the perspective of konkatsu [D], Hunan University, 2016. 04. 25

[8] http://www.sohu.com/a/212938594 171986

[9] P . Wenbin et al. Blind-date economy prospering in the Yangtze River Delta [J]. Reporters' Notes. 2006, no.08, pp.16-17.

[10] R . Jingxian. An insight into Japanese youths' marriage views from the perspective of konkatsu [D], Hunan University, 2016. 04. 25

[11] W . Linfang. A postgraduate study on passive participation and negative involvement in blind dates - a perspective based on social exchange theory [J]. Modern Communication, 2017.06.30, pp.166-167..

[12] Y . Mori. From"I want to marry one day" to konkatsu - according to the investigation of the seventh marriage and childbirth [J]. Life Welfare Research [J], 2013.06, no.84, pp.1-15.

[13] R. Jingxian. An insight into modern Japanese youths' marriage views from the perspective of konkatsu [D]. Hunan University, 2016. 04. 25

[14] Y . Mori. From"I want to marry someday" to konkatsu - according to the investigation of the seventh marriage and childbirth [J]. Life Welfare Research, 2013.06, no.84, pp.1-15.. 